\title{
SOBRE LA NATURALEZA JURÍDICA DE LA INCONSTITUCIONALIDAD
}

\author{
Carla Huerta Ochoa \\ Universidad Nacional Autónoma de México (México)
}

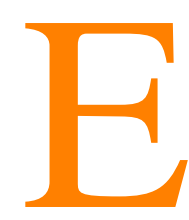

1 tema elegido parece no tener relación alguna con la problemática de los sistemas normativos o relación con la lógica deóntica, pero esto no es así. Por el contrario, pienso demostrar a continuación que el problema de la constitucionalidad de las normas no se puede comprender sino es desde una concepción del Derecho como sistema jurídico, y dado que este concepto es el que permite la interrelación de las normas, éstas pueden y deben ser analizadas mediante la lógica deóntica para resolver los problemas de contradicción normativa.

El análisis sobre la naturaleza jurídica de la inconstitucionalidad me permitirá sostener la hipótesis de que existen diversos tipos de conflictos de normas, y que no siempre existe una contradicción entre las mismas, por lo cual será necesario revisar conceptos tales como sistema jurídico, norma, contradicción y validez, para poder establecer un concepto de conflicto normativo generalmente aceptado.

Cuestionarse la posibilidad de contradicción entre normas es día con día de mayor relevancia, principalmente por la internacionalización del Derecho. La consecuencia ha sido el incremento de la complejidad de los ordenamientos jurídicos, principalmente debido al hecho que no todos los órganos creadores de normas están regulados por la Constitución, como es el caso del derecho de la Unión Europea, por ejemplo.

El problema de la pluralidad de fuentes, aunado a la sobrerregulación que se ha dado en los últimos tiempos con el objeto de prever todas las situaciones posibles, ha generado una incertidumbre no solamente en cuanto al volumen del universo normativo que rige en un determinado país, sino también problemas de incompatibilidad entre las normas de un mismo sistema jurídico. Estos problemas son lo que aquí denomino conflicto normativo. 
El presente cuestionamiento parte de la premisa de que una contravención del derecho secundario respecto de la Constitución no es algo deseable ya que ésta se configura como la norma suprema del ordenamiento jurídico. Desde el punto de vista formal es importante que las normas del derecho secundario sean acordes con la Constitución, es por ello que éstas deben cumplir con las condiciones establecidas para su elaboración, en el caso contrario son inconstitucionales y deben ser declaradas inválidas. Desde el punto de vista material la compatibilidad de dichas normas es obligatoria debido a la supremacía de la Constitución. La consecuencia de su inadecuación debería ser la nulidad de la ley.

La constitucionalidad de las leyes fomenta la seguridad jurídica y fortalece la eficacia del ordenamiento jurídico. Por dichas razones los tribunales deben velar por la correcta aplicación de las normas jurídicas, esto se logra mediante controles dentro y fuera del Poder Judicial, pero especialmente mediante el control de la constitucionalidad.

Lo que pretendemos hacer ver es que no es la norma secundaria la que viola la Constitución en los casos en que se trata de un conflicto de orden formal, la norma no es quien ha violado el procedimiento, ha sido el legislador que ha desatendido un precepto constitucional en la elaboración de la ley ordinaria. Si la norma es declarada inconstitucional por el órgano competente esto se debe más bien al hecho de que en la elaboración de la misma el procedimiento no fue cumplido y éste es inconstitucional, no la norma, es por ello que al declarar la inconstitucionalidad del procedimiento, el producto de la misma, la norma en cuestión, debe ser eliminada y el procedimiento debe reponerse desde donde se cometió la violación o bien reiniciarse. De tal forma que por costumbre es la norma anulada la que se tiende a llamar inconstitucional, siendo que más bien la norma es anulada como efecto de la inconstitucionalidad del procedimiento de su elaboración, el vicio se encuentra en el procedimiento de elaboración y afecta la aplicabilidad de la norma. De cualquier forma nos encontramos ante un tipo especial de conflicto normativo.

El caso de la inconstitucionalidad material es completamente diferente, es por ello que me gustaría antes de revisar este caso y determinar si existe una contradicción o no entre la norma suprema y la ley ordinaria, establecer qué tipos de conflictos normativos son posibles.

\section{El concepto de norma}

Quizá sería conveniente comenzar por definir el objeto que pretendemos analizar, y si queremos hablar de conflictos normativos debemos primero saber qué son las normas. 
Las normas son los elementos que conforman al sistema jurídico, se caracterizan por el hecho de que establecen determinadas conductas como obligatorias, prohibidas o permitidas, es decir, por su carácter deóntico; su contenido es variable, son las conductas a que se refieren, puede ser un dar, un hacer o un no hacer. Las normas jurídicas se distinguen de otro tipo de normas por su obligatoriedad, ya que ésta está vinculada a un aparato institucionalizado que ejerce un control y puede obligar al cumplimiento de la norma aun en contra de la voluntad del sujeto obligado.

Por lo tanto es importante concebir al Derecho como un sistema jurídico, ya que esto permite que sus elementos componentes se interrelacionen para formar una unidad; por lo mismo, las normas jurídicas no pueden comprenderse aisladamente, sino solamente en relación con las demás normas. De dicha concepción se derivan ciertas propiedades formales del sistema, tales como: la completitud, la coherencia, la consistencia y la independencia.

La completitud es más bien una pretensión de que todos los casos posibles estén previstos en el ordenamiento jurídico y para cada uno de ellos exista una solución. La realidad jurídica no es ésta, las lagunas existen y se configuran como un grave problema que debe enfrentar el juez, pero en este ámbito no podemos realmente hablar de conflictos normativos, salvo cuando la labor interpretativa o integradora del juez produjera una norma que pudiera contravenir otra.

La coherencia del sistema es probablemente la propiedad más importante para el presente análisis, dado que debe permitir la relación de las normas de manera lógica y congruente; se puede decir que el sistema carece de ella cuando se prevén soluciones diversas e incompatibles para uno o varios casos. La coherencia, por lo mismo, se convierte en una propiedad en el plano de la razonabilidad, que implica la congruencia material de las normas del sistema.

Sería conveniente distinguir la coherencia de la consistencia, trabajo nada fácil ya que constantemente se utilizan como sinónimos. La coherencia es una propiedad formal en sentido positivo; por el contrario la consistencia se define como una propiedad negativa, como la ausencia de contradicciones, cuya presencia de cierta forma no nos permite negar que representa una incoherencia en el sistema; sin embargo, estamos ante dos características diferentes y los problemas que se deriven de ellos deben enfrentarse de distinta manera.

La dificultad inicial de distinguir coherencia y consistencia radica en la estrecha relación que existe entre ambos conceptos, pues como mencionábamos, un sistema que contiene normas contradictorias puede ser calificado como incoherente, dado que no es razonable que un sistema jurídico prevea conductas o consecuencias incompatibles para un mismo caso. Por otra 
parte, que un sistema sea incoherente no quiere decir que entre sus normas existan contradicciones, sino simplemente que los principios que la informan no son congruentes; como, por ejemplo, establecer como religión oficial la católica y permitir la poligamia no sería razonable, o que la Constitución establecezca el principio democrático y, sin embargo, no prevea procedimientos para convocar a elecciones.

Parece difícil aceptar la posibilidad de conflictos normativos, ya que una situación tal hace parecer al sistema como incoherente y desvirtúa su unidad, sin embargo, no por ello debemos acusar de irrracional al legislador, sino que quizá deberíamos contemplarlo como una posible inconsistencia del sistema y dichas inconsistencias pueden ser resueltas.

\section{El concepto de conflicto normativo}

«Conflicto normativo» es un concepto de naturaleza vaga, por lo que mediante la descripción de los elementos básicos del mismo, pretendemos circunscribirlo para efectos del presente trabajo.

La cuestión se plantea a partir de la duda sobre si existe la posibilidad de que en un ordenamiento jurídico sean simultáneamente aplicables a un mismo caso dos normas y que entre éstas exista una contradicción entre sus contenidos, en virtud de lo cual solamente una de ellas puede ser aplicada. ¿Cómo debe actuar el órgano competente, ya que no solamente debe elegir sólo una norma, sino que al hacerlo lo más probable es que se incurra en una violación de la otra norma?

El primer reto a enfrentar es encontrar un concepto de conflicto normativo que nos permita responder a diversos interrogantes, por lo cual debemos comenzar por reflexionar si realmente existe una diferencia entre los conceptos de conflicto normativo, colisión entre normas, contradicciones, violación, infracción, etc., los cuales la doctrina tiende a utilizar como sinónimos. ¿Realmente existen diversos tipos de conflictos entre las normas? Mi respuesta es que sí, y no solamente es relevante sino que mi tesis va más allá, dado que asumo que a cada tipo de conflicto corresponde una forma de resolución distinta. Más aún, considero que algunos de estos conceptos no son aplicables a normas, como es el caso de contradicción en el sentido lógico, dado que no son las normas las que se contradicen, sino los enunciados que las expresan.

El problema de la contradicción puede ser resuelto mediante la confrontación de los enunciados en cuestión con la realidad y así comprobar cuál es verdadero y cuál no. Con ayuda de la Lógica podrá también comprobarse que uno de los enunciados (el verdadero) hace al otro (al falso) imposible. Los conceptos en cambio sí pueden contradecirse, lo cual implica que se excluyen mutuamente, pero no que uno haga imposible al otro. 
Las normas en cambio pueden ser válidas o inválidas y dos normas en colisión pueden ser simultáneamente válidas, mientras que los enunciados que se contradicen no pueden ser ambos verdaderos.

Respecto de los conceptos de «Colisión» y de «Conflicto» es un tanto diferente, porque ambos son aplicables a las normas y frecuentemente se utilizan como sinónimos. El punto de partida es que en un ordenamiento jurídico se pueden presentar diversos tipos de conflictos.

Un conflicto normativo (sensu largo) se presenta cuando dos o más normas son formal o materialmente incompatibles (este sería el género), en este tipo de conflictos puede o no presentarse una contradicción (normativa), sin embargo, existen casos en que el conflicto deriva de un problema formal y la norma «imperfecta» puede ser o es declarada nula, a estos casos es a los que llamaré «infracción».

En el caso de una contradicción normativa estamos ante un verdadero conflicto normativo, porque se configura como una contradicción material; esto se presenta cuando dos o más normas tienen el mismo ámbito de aplicación y sus «contenidos normativos» son incompatibles, es decir, que las normas en conflicto no pueden ser cumplidas al mismo tiempo, el cumplimiento de una produce necesariamente la desobediencia de la otra. En dicho caso debe decidir el juez cuál es la norma válida para el caso, y por lo mismo, la aplicable.

Al hablar de «contradicción normativa», esto significa que dos normas válidas, potencialmente aplicables, tienen contenidos incompatibles, como, por ejemplo, cuando una norma establece que algo está prohibido y otra obliga a la realización de la misma conducta. Es evidente que solamente una puede ser cumplida y de la otra se derivará una sanción coactiva; esta situación se convierte en un dilema para el sujeto normativo y, por otra parte, configura un problema de eficacia para el sistema. Se puede decir que entre estas normas se genera un «conflicto obligacional» o un «conflicto de sanciones». En estos casos nos encontramos ante conflictos entre los operadores deónticos de las normas correspondientes o sus consecuencias jurídicas. Es, por ello, que nos encontramos ante una contradicción en el Derecho Positivo, a pesar de que aún no existe un acuerdo sobre la posibilidad de que existan las contradicciones normativas.

Las contradicciones normativas pueden presentarse de dos formas: una es como «Conflictos normativos» (sensu strictu) o como «Colisiones entre normas» $\left(\right.$ Normkollisionen $^{1}$ ), las cuales se distinguen en función de la estructura de las normas en conflicto.

${ }^{1}$ Aquí estamos utilizando la clasificación y terminología elaborada por Alexy en «Theorie der Grundrechte», $2^{\mathrm{a}}$ edición, 1994, p. 71 ss. 
Los conflictos normativos (s.s.) surgen del enfrentamiento entre dos reglas. Las formas de solucionar este conflicto es o bien que una de las dos reglas prevea una cláusula de excepción (en cuyo caso no podemos decir que el conflicto exista si la cláusula de excepción es prevista de antemano por el Legislador, sino solamente cuando debe ser introducida por el juez mediante sus facultades de interpretación o integración), o que una de las dos reglas sea declarada inválida.

En los casos de una colisión normativa no se trata de un problema de validez formal, sino más bien del choque entre dos principios, que pueden poseer un peso específico diferente y cuyos contenidos son incompatibles. La solución se encuentra en la ponderación de ambos principios; la prelación de los mismos se determina en la ponderación ya que el peso o fuerza de los mismos varía dependiendo de los principios mismos en colisión en un caso determinado.

Los conflictos, por otra parte, pueden también darse entre normas del mismo o de distintos rangos, por lo que el conflicto puede depender de la posición de la norma, así como la solución del mismo. En la tipología que acabamos de exponer brevemente no se ha considerado esta distinción, sino que para la elaboración del siguiente esquema nos referimos solamente a conflictos entre normas del mismo rango.

De manera esquemática:

conflictos normativos (1.s.)

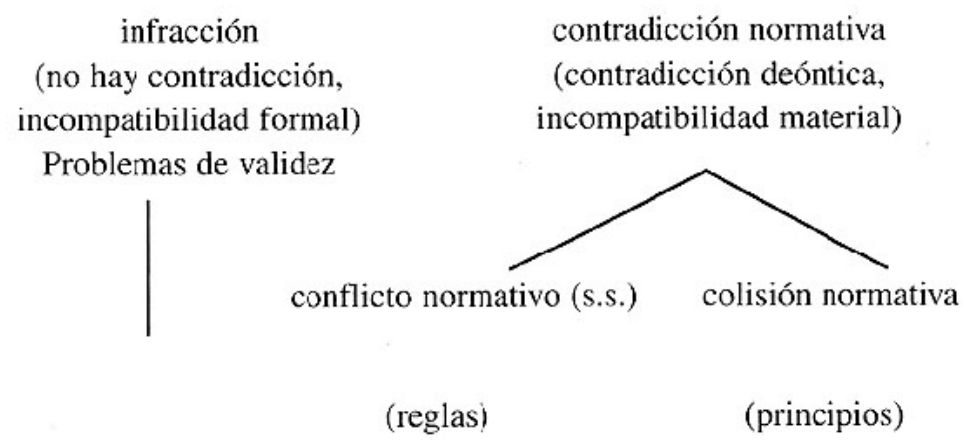

Esta clasificación y su correspondiente conceptualización es posible porque pueden existir dos tipos de problemas diversos entre las normas, como anteriormente mencionábamos. Los problemas formales se dan cuando en la elaboración de una norma se comete un error en el procedimiento, su solución no es problemática dado que la conformidad de la norma al ordenamiento jurídico puede ser comprobado por el órgano competente y la norma defectuosa puede ser declarada nula o inaplicable. Por eso es que pode- 
mos afirmar que los casos de conflictos formales entre una norma y la norma jerárquicamente subordinada a ella no constituyen una contradicción, sino un defecto procedimental. De cualquier forma nos encontramos ante una infracción, ya que las condiciones de su elaboración no fueron debidamente cumplidas. Esto no nos lleva a una «contradicción formal», pero sí a la invalidez de una norma. La invalidez se deriva del incumplimiento de las normas procedimentales. Por lo tanto, hablar de un «conflicto» entre estas normas es metafórico, ya que el sujeto de la infracción es el órgano productor de la norma, y no la norma misma.

Un problema mayor es aquel que enfrentamos cuando nos encontramos ante una incompatibilidad material entre dos normas aplicables, ya que se pueden presentar diversos tipos de incompatibilidades entre los contenidos de dichas normas. Se podrá expresar de la siguiente manera: La situación en la cual dos o más normas son aplicables, cuyos contenidos están vinculados a un operador deóntico que es «incompatible» con el operador deóntico de la otra norma, es una contradicción normativa. Podrámos quizá hablar de una «contradicción deóntica», ya que se configura una contradicción entre diferentes formas del «deber». Sin embargo, lo anterior no significa que algo así como un «deber contradictorio» sea posible. La contradicción lógica no se establece entre los operadores deónticos, sino entre las conductas que éstas ordenan. Que la conducta debida, prohibida o permitida por ambas normas no pueda realizarse simultáneamente, implica el incumplimiento de al menos una de las normas. Por lo mismo no pueden ser aplicadas al mismo tiempo, y el cumplimiento de una de ellas puede significar la infracción de la otra.

La tesis que sostengo es que una colisión normativa solamente se produce cuando se aplican normas, normas válidas, y esta idea sólo es posible en relación a intereses individuales en un caso específico, es decir, no existen en abstracto. Se trata de un problema práctico, que solamente puede presentarse en el mundo fáctico cuando se deben aplicar las normas, no en el plano teórico. Cuando el legislador no actúa racionalmente y de manera descuidada establece una norma incompatible con otra, éstas colisionan solamente en el momento de su aplicación.

Si las normas colidieran en el plano normativo, debería ser posible eliminarlas automáticamente del ordenamiento jurídico, si la nulidad «ipso iure» fuese posible, y quizá ésta sería una tarea más propia del legislador que del juez y se llevaría a cabo como un control previo de la constitucionalidad de una norma, pero en ese momento estaríamos hablando de un proyecto de norma, de modo que el conflicto no sería real sino solamente posible. Un control de las normas, ya sea por el juez o el legislador, cuya vocación fuese eliminar aquellas disposiciones que se encuentren en una situación de conflicto 
en el plano normativo, se configuraría como un sistema de depuración del ordenamiento jurídico con el objeto de mantener la coherencia del mismo.

\section{El problema de la inconstitucionalidad}

Debemos distinguir entre los problemas de constitucionalidad material y formal, ya que en este segundo caso no existe una contradicción normativa, sino simplemente el incumplimiento de la norma por la autoridad (competente o no) de las normas procedimentales y por lo tanto estamos más bien ante un problema de validez que de constitucionalidad; la norma en caso de un vicio en el procedimiento de elaboración deberá ser declarada nula conforme al procedimiento establecido. En el esquema presentado se encontraría en la clasificación de «infracción» cuyas soluciones se presentan dependiendo del sistema correspondiente mediante la nulidad o la inaplicación de una de las normas secundarias en cuyo procedimiento de elaboración se cometió la correspondiente infracción a la norma superior.

Los problemas de inconstitucionalidad material solamente se pueden presentar en la forma de contradicción normativa señalada en el esquema como conflicto normativo en sentido estricto, puesto que se trata de la contradicción entre dos reglas y la solución se presenta estableciendo una cláusula de excepción a la norma constitucional, facultad que solamente posee el órgano competente para interpretar e integrar, en su caso, la Constitución; o bien, derogando la norma secundaria que se ha declarado inconstitucional, ya que en este caso el principio de jerarquía normativa opera en favor de la Constitución.

En el caso de contradicción entre principios la situación no puede ser llamada inconstitucionalidad, ya que la colisión normativa no puede darse sino entre normas del mismo rango, por lo tanto no se puede configurar como un enfrentamiento entre la ley y la Constitución, ya que en dicho caso en virtud del principio de jerarquía normativa operaría de inmediato la derogación de la ley que contuviera los principios violatorios de la norma suprema. Por otra parte, en el caso de una colisión entre principios de la Constitución, no podemos hablar de inconstitucionalidad, ya que al estar dichos principios previstos en la misma son constitucionales. Lo que sucede es que en un caso específico y por circunstancias determinadas no es posible aplicar ambos de manera simultánea. La contradicción entre ambos principios se resuelve con la ponderación de los mismos, lo cual significa que para el caso en cuestión, uno va a ceder frente al otro dependiendo de la fuerza que el juez atribuya a cada uno, sin embargo ambos siguen siendo igual de válidos y vigentes que antes, lo que varía es la eficacia específica.

Así es que podemos afirmar que no toda inconstitucionalidad plantea una contradicción, aunque sí un conflicto normativo conforme a la defini- 
ción anteriormente propuesta, dado que depende de la naturaleza de la misma para poder determinar si existe o no una contradicción y la forma de determinarla será mediante la lógica deóntica.

\section{Sobre la naturaleza de la contradicción}

Entender el ordenamiento jurídico como un sistema de enunciados permite hacer afirmaciones sobre la validez de las normas. Sin embargo, la invalidez de una de sus normas no se deriva lógicamente de la validez de la otra en un conflicto, como la falsedad de un enunciado se deriva de la verdad del enunciado con el que se encuentra en contradicción.

Los enunciados normativos son la expresión lingüística de las normas, y las normas son el significado de éstos. Dichos enunciados expresan un deber ser (ya sea una obligación, una prohibición o un permiso), por lo tanto, no son verificables y no pueden ser contrastados con la realidad, por ello es que no podemos predicar su verdad, no son ni verdaderos, ni falsos.

Para Alexy ${ }^{2}$ el concepto semántico de norma es el adecuado para responder a la pregunta acerca de si dos normas son lógicamente compatibles, ya que la norma es el significado del enunciado normativo. Por otra parte, este concepto permite deslindar los conceptos de validez y de norma. Si el concepto de validez se incorporara a la norma, entonces no podríamos afirmar que una norma no es válida.

El hecho de que la existencia de normas que se contradicen sea o no una contradicción lógica es cuestionable; sin embargo, no podemos dudar de que se trata de un conflicto. La contradicción no se encuentra en el hecho de que dos normas se contradigan, sino en el hecho de que sus contenidos son contradictorios y no son realizables al mismo tiempo; por lo mismo las normas no se pueden aplicar simultáneamente ${ }^{3}$.

Si la contradicción lógica solamente puede verificarse entre enunciados de los cuales se puede predicar la verdad, solamente podría darse entre enunciados normativos, es decir, entre enunciados de validez (Geltungssätze). Si describimos la situación de la siguiente manera: GOp $\wedge \neg$ GOp, significaría que la misma obligación es válida y no es válida al mismo tiempo, lo cual es lógicamente imposible. De modo que la contradicción lógica se puede entender de distintas maneras: 1. como la contradicción entre contenidos normativos, como en von Wright o Weinberger, o 2. como la contradicción entre dos enunciados sobre validez, como en Sieckmann.

\footnotetext{
${ }^{2}$ Alexy, Op. cit., p. 49.
}

${ }^{3}$ Para Weinberger la inconsistencia de enunciados normativos significa que por razones lógicas éstos no pueden ser cumplidos al mismo tiempo. «Rechtslogik», 1989, p. 65. 
Dado que no podemos hablar de la verdad de una norma, porque las normas no son entidades ontológicas, sino deónticas, nos referimos a su validez. Sin embargo, el hecho de que las normas carezcan de un valor de verdad, no es impedimento alguno para calificar a los conflictos normativos como contradicciones lógicas entre sus contenidos o entre dos enunciados de validez o para determinarlos y analizarlos mediante la lógica deóntica.

Las reglas de la lógica, sin embargo, no son aplicables a la solución de los conflictos normativos, sino simplemente para identificarlos; la solución depende principalmente del tipo de conflicto de que se trate.

Si el conflicto normativo significa la imposibilidad de cumplir simultáneamente dos normas en conflicto, nos encontramos ante un problema de índole práctica, ya que ambas normas son válidas. Si la contradicción normativa se contempla como una contradicción lógica entre dos enunciados de validez o entre contenidos normativos, entonces debe ser resuelta, ya que ambas normas no pueden ser aplicadas al mismo tiempo y el órgano aplicador debe elegir una de ellas y justificar su decisión.

La cuestión queda aún abierta. Si un conflicto normativo no implica necesariamente una contradicción, ¿entonces qué es? ¿Podría configurarse como una «contradicción práctica», dado que las normas no pueden ser cumplidas simultáneamente? O quizá podemos llamarlo una «contradicción deóntica», pero de ser así, ¿qué consecuencias se derivarían de ello? No cabe duda de que existen diversos tipos de conflictos normativos y diversas formas de contradicciones, es por ello que no existe acuerdo sobre su denominación. Pero de cualquier forma cada tipo de conflicto debe ser identicable y tratado de una manera distinta. 